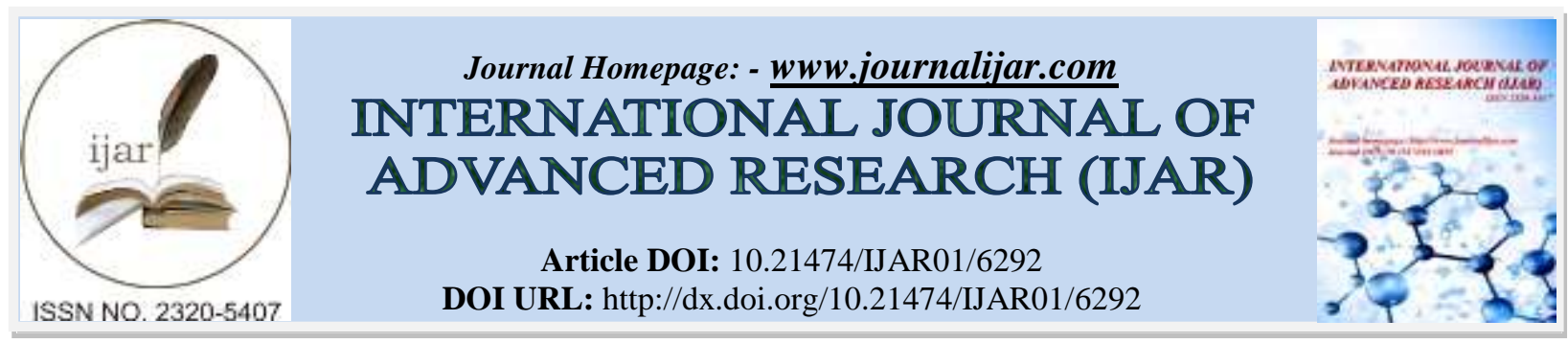

RESEARCH ARTICLE

\title{
TO COMPARE TNO VERSUS RANDOT TEST FOR MEASURING STEREOACUITY WHILE SCREENING AIRLINE PILOTS.
}

\author{
Wg Cdr Sapna Raina and Col Anirudh Singh.
}

AFCME, New Delhi.

\section{Manuscript Info}

Manuscript History

Received: 12 November 2017

Final Accepted: 14 December 2017

Published: January 2018

Key words:-

TNO versus Randot stereotests

\section{Abstract}

Background: Stereoacuity or depth perception is an important visual parameter which is often not tested during ophthalmic examinations but assumes enormous importance when dealing with critical occupations like flying. The importance of stereoacuity testing in pilots is recently been acknowledged however no official norms exist for universal testing of stereoacuity levels in pilots. We proposed to evaluate TNO with Randot stereacuity test in all airline pilots during their routine medical examination. Methods: A total of 515 airline pilots( 431 males and 84 females) with no previous ocular medical or surgical history were prospectively assessed using TNO and Random dot stereoacuity tests. Result: TNO and RDT correlated positively and significantly at .01 level. There was no statistically significant difference found between males and females. Conclusion: Both TNO and Randot stereoacuity compared favourably in testing stereoacuity testing and can be used universally however TNO test did show an added advantage of rechecking the colour perception of airline pilots as those with colour blindness cannot discriminate TNO test.

Copy Right, IJAR, 2018,. All rights reserved.

\section{Introduction:-}

Stereopsis is a concept recently popularized however known since time immemorial. It is the recent interest in the depth perception and 3D culture which is propelling the industry towards the 3D feature films and virtual reality games and classes. With this the renewed interest of testing of stereoacuity has come forward. Few test available for testing stereoacuity have not been standardized universally and require clinical trials in various groups to consolidate universal norms. The importance of depth perception in certain critical occupations like airline pilots cannot be overemphasized.

Stereotesting is not being done routinely for airline pilots and it is only recently that studies have bought forward the importance of having a fine degree of stereoacuity in these occupations. In addition to diagnosing low levels of stereoacuity these tests can also indirectly indicate other binocular abnormalities like anisometropia, amblyopia and strabismus. Yet stereoacuity testing has not become universal due to lack of standardized test and relative difference between the different tests. TNO test though popular for testing stereoacuity is limited by the red green perception. Randot due to its various modifications sometimes gives false positives. ${ }^{1-4}$ In view of the above it was decided to screen the healthy airline pilots coming for routine medical exam with both TNO and Randot stereoacuity tests and compare the stereoacuity levels and assess the efficiency and practicality. 


\section{Methods:-}

This prospective study was conducted at the Ophthalmology department of our institution between Jan 2017 and June 2017. All participants were included from the routine airline pilots reporting for their medical examination prior to their flying training. A total of 515 airline pilots( 431 males and 84 females) with no previous ocular medical or surgical history were prospectively assessed using TNO and Random dot stereoacuity tests. All the pilots had 20/20 vision in both eyes with or without corrective spectacles.

Informed consent was taken from all the participants of the study. The study conformed to the tenets of declaration of Helsinki.

Routine ophthalmology examination was conducted as per the requirements for flying standards. Vision assessment was done and refraction done with cycloplegia where required. Slit lamp examination was done to rule out any anterior segment abnormality like corneal opacity, lens opacity or angle abnormality. Fundus was screened in all cases. Cover-uncover test was done to rule out any tropia/phoria and such cases if detected were excluded from the study.

The participants were explained about the TNO and random dot stereoacuity tests. As a randomized study first TNO test was done with red green spectacle. TNO test is based on red green anaglyph principle and it proves a limitation in persons with red green colour blindness. So in addition it can give an indicator for partial or complete red green colour blindness in individuals having a rather low stereoacuity levels in testing. Such cases were excluded from the current study and were subjected to other tests for colour blindness namely Ishihara chart and Martin lantern test. The levels of stereoacuity was recorded based on the response from participant and telling about the missing part of the circle. Subsequently Random dot test was done with polarized spectacles and the level of stereoacuity recorded based on the response.

\section{Result:-}

A total of 515 airline pilots (431 males and 84 females) in the age range of 21 years to 25 years were included in the study. The stereocuity levels were beween 60 to $240 \mathrm{sec}$ of arc with TNO and between 12.5 and $40 \mathrm{sec}$ of arc with Random dot test. Both the tests correlated positively and significantly at 0.01 level. [Table 1]

Table1:- Pearson correlation coefficient between TNO and Random dot stereotest.

\begin{tabular}{|c|c|c|c|}
\hline \multicolumn{4}{|c|}{ Correlations } \\
\hline & & RDT & TNO \\
\hline \multirow[t]{3}{*}{ RDT } & Pearson Correlation & 1 & $.551^{*}$ \\
\hline & Sig. (2-tailed) & & .000 \\
\hline & $\mathrm{N}$ & 514 & 514 \\
\hline \multirow[t]{3}{*}{ TNO } & Pearson Correlation & $.551^{* * \pi}$ & 1 \\
\hline & Sig. (2-tailed) & .000 & \\
\hline & $\mathrm{N}$ & 514 & 515 \\
\hline
\end{tabular}

There was no statistically significant difference found between males and females. [Table 2]

Table 2:- Standard deviation between Random dot and TNO tests

\begin{tabular}{|c|c|c|c|c|c|}
\hline \multicolumn{6}{|c|}{ Group Statistics } \\
\hline & Gender & $\mathbf{N}$ & Mean & Std. Deviation & Std. Error Mean \\
\hline \multirow[t]{2}{*}{ RDT } & $\mathbf{M}$ & 431 & 19.9675 & 7.67714 & .36979 \\
\hline & $\mathbf{F}$ & 84 & 19.6964 & 8.62925 & .94153 \\
\hline \multirow[t]{2}{*}{ TNO } & $\mathbf{M}$ & 431 & 1.3819E2 & 68.64449 & 3.30649 \\
\hline & $\mathbf{F}$ & 84 & 1.5286E2 & 96.97312 & 10.58064 \\
\hline
\end{tabular}

Independent samples test (Levene's test for equality showed a significance of 0.002 with TNO and 0.396 with Random dot. T-test for equality of means showed a 95\% confidence interval of -1.56571 with random dot and 31.99849 with TNO test. 


\section{Discussion:-}

Stereoacuity or depth perception is a vision faculty which has lately gained importance due to the interest in $3 \mathrm{D}$ technology which has become a part of our lives. The increasing research in $3 \mathrm{D}$ technology in cinema, education and medical science has made stereoacuity an important part of our everyday lives. It is but imperative that stereoacuity be present at the highest levels to experience this $3 \mathrm{D}$ world.

Various tests to test the stereoacuity have become popular like the TNO test based on red green anaglyph principle, Random dot stereotest with Polaroid glasses, Lang's stereotests, Titmus fly test etc. The reliability of these tests varies in different age groups and intellect of test subjects. It is important therefore to have standard and uniform criteria to test the stereoacuity levels. ${ }^{5-7}$ The comparability of one of the two most popular stereotest i.e., TNO and Random dot on various spectrum of test subjects on a large population base can give us criteria for testing.

The criticality of stereotesting in certain occupations like flying cannot be ignored. There have been numerous incidents of air mishaps where the pilots faltered during air or landing maneuvers eg. during flaring. The literature is flooded with reports of one eyed pilots who managed to fly considerable sorties but it also points out the eventual mishaps in most of the cases. With the autopilots assisting in the landing and take off; most of the work is taken over by the technology yet in instances where human judgement is required particularly in times of distress or unusual situations the binocular assessment in complex maneuvering comes into play. With many lives at stake it is but natural to have stringent and uniform criteria to test the stereoacuity levels in airline pilots.

So far only the US has criteria for testing stereoacuity in US military services but the Federal aviation authority of US has no such criteria for airline pilots nor do countries like Canada, UK and India. In this regard studies are definitely required to substantiate the importance of stereoacuity in day to day lives and in particular for occupations requiring a high degree of binocular skills.

Stereotest have to be standardized and different tests tested in various groups to come to any conclusion. Our study compared the two most popular stereotest TNO and Random dot test in young healthy airline pilots reporting for routine medical.

Previous study by Ceyhan et al in Balkan Military review 2009 compared TNO with Titmus test in young children below 14 years of age and also concluded that the results of the Titmus test is reported to be "significantly correlated" to Randot Preschool Stereoacuity tests which is reported to be superior to other stereoacuity tests. ${ }^{8-11}$ The study also derived thatTitmus test is reliable to quantify the fine stereopsis and easy to apply to healthy subjects of 4-14 years of age.

TNO test may sometimes give false negatives due to a colour perception deficiency in the test subjects as there is a requirement of red green spectacles in this test. In our study all the participants were tested for colour perception with Ishihara test before doing TNO test. The candidates tested similar on both tests in terms of understanding the test, repeatability, time taken. The stereocuity levels were lower with Random dot as compared to TNO (beween 60 to $240 \mathrm{sec}$ of arc with TNO and between 12.5 and $40 \mathrm{sec}$ of arc with Random dot test) however both the tests correlated positively and significantly at 0.01 level.

This study implies that both TNO test as well as Random dot stereotest can be used for testing fine levels of stereoacuity. Either test could be uniformly used depending on the availability, however TNO gives additional marker for colour deficiency which may be an important criteria in occupations like flying. 


\section{References:-}

1. von-Noorden GK, Campos E. Binocular vision and space perception. In: Binocular Vision and Ocular Motility. St Louis, Mosby Inc, 6th edition, p7-38, 2002

2. Simons K. A comparison of the Frisby, Random-Dot E, TNO, and Randot circles stereotests in screening and office use. Arch Ophthalmol 99 (3):446-52, 1981

3. Ohlsson J, Villareal G, Abrahamsson M, Cavazos H, Sjöström A, Sjöstrand J. Screening merits of the Lang II, Frisby, Randot, Titmus, and TNO stereo tests. J AAPOS 5(5):316-322, 2001

4. von-Noorden GK, Campos CE. Examination of the patient-V. In: Binocular vision and ocular motility. St Louis; Mosby Inc, 6th edition, 300, 2002

5. Fawcett,SL, Birch, E.E.,Validity of the Titmus and randot circles tasks in children with known binocular vision disorders. J AAPOS 7(5):333-338, 2003

6. Larson WL. Effect of TNO red-green glasses on local stereoacuity. Am J Optom\& Physiol Optics 65 (12) 946950, 1988

7. Fricke T, Siderov J. Non-stereoscopic cues in the Random-Dot E stereotests: results for adult observers. Ophthalmic Physiol Opt 17:122-7,1997

8. Antona B, Barrio A, Sanchez I, Gonzalez E \& Gonzalez G. Intraexaminer repeatability and agreement in stereoacuity measurements made in young adults. Int J Ophthalmol 2015; 8: 374-381.

9. Simons K. A comparison of the Frisby, Random-Dot E, TNO, and Randot circles stereotests in screening and office use. Arch Ophthalmol 1981; 99: 446-452.

10. Fawcett SL \& Birch EE. Validity of the Titmus and Randot circles tasks in children with known binocular vision disorders. J AAPOS 2003; 7: 333-338.

11. Leat SJ, Pierre JS, Hassan-Abadi S \& Faubert J. The moving Dynamic Random Dot Stereosize test: development, age norms, and comparison with the Frisby, Randot, and Stereo Smile tests. J Pediatr Ophthalmol Strabismus 2001; 38: 284-294. 